and $33 \%$ of patients treated with the new regimen. ${ }^{11}$ The authors concluded that outcome in control patients was significantly improved compared with historical experience and that the new treatment regimen including extracorporeal carbon dioxide removal conferred no extra survival benefit. ${ }^{12}$

The conditions that must be met before further trials of extrapulmonary gas exchange can begin are daunting and make the prospect of randomised, controlled evaluation remote. Technology and clinical practice should be stable and standardised; trial protocols should direct patient selection and timing of intervention and dictate end points for failure and stopping treatment. ${ }^{13}$ The emergence of alternative treatments such as inhaled nitric oxide and exogenous surfactant preparations will limit recruitment of patients. Centres would need experience of applying new treatments in such critically ill patients, yet be prepared to forgo their use in control patients even when conventional management is obviously failing, thereby giving rise to the same ethical dilemmas that affected assessment of these techniques in neonates. ${ }^{5}$

Further studies are now required to define maximal conventional treatment and its outcome in patients meeting accepted criteria for treatment with extracorporeal membrane oxygenation, particularly as more sophisticated mechanical ventilatory support is evolving, thereby rendering historical controls invalid. A European registry of all forms of extrapulmonary lung support in adults should be established.

Emphasis should be given to developing severity scoring systems in acute lung injury, which would provide advanced warning of deterioration and poor prognosis. Responsibility lies with regional referral centres to identify and transfer patients likely to benefit from adjuvant support treatments. More widespread application of these invasive techniques in the primary admitting units cannot be recommended until the technology has stabilised and the place of less invasive alternative treatments becomes clearer.

\section{KENNETH M SIM} Research fellow

TIMOTHY W EVANS

Reader in critical care

Unit of Critical Care,

National Heart and Lung Institute,

Royal Brompton National Heart and Lung Hospital,

London SW3 6NP

1 Suchyta MR, Clemmer TP, Orme JF Jr, Morris AH, Elliott CG. Increased survival of ARDS patients with severe hypoxaemia (ECMO criteria). Chest 1991;99:951-5.

Lachmann B. Open up the lung and keep the lung open. Intensive Care Med 1992;18:319-21.

3 Evans TW, Keogh BF. Extracorporeal membrane oxygenation: a breath of fresh air or yesterday' treatment? Thorax 1991;46:692-4.

4 Custer JR, Bartlett RH. Recent research in extracorporeal life support for respiratory failure. ASAIO fournal 1992;38:754-71.

5 Elliott SJ. Neonatal extracorporeal membrane oxygenation: how not to assess new technologies. Lancet 1991;337:476-7.

6 Gattinoni L, Pesenti A, Mascheroni D, Marcolin R, Fumagalli R, Rossi F, et al. Low-frequency positive-pressure ventilation with extracorporeal $\mathrm{CO}_{2}$ removal in severe acute respiratory failure. fAMA 1986;256:881-6.

7 Brunet F, Mira JP, Belghith M, Lanore JJ, Schlumberger S, Toulon P, et al. Effects of aprotinin on hemorrhagic complications in ARDS patients during prolonged extracorporeal $\mathrm{CO}_{2}$ removal. Intensive Care Med 1992;18:364-7.

8 Young JD, Dorrington KL, Blake GJ, Ryder WA. Femoral arteriovenous extracorporeal carbo dioxide elimination using low blood flow. Crit Care Med 1992;20:805-9.

9 Conrad SA, Eggerstedt JM, Morris VF, Romero MD. Prolonged intracorporeal support of gas exchange with an intravenacaval oxygenator. Chest 1993;103:158-61.

10 Hattier BG, Johnson PC, Sawzik PJ, Shaffer FD, Klain M, Lund LW. Respiratory dialysis-a new concept in pulmonary support. ASAIO fournal 1992;38:M322-5.

11 Morris AH, Wallace CJ, Clemmer TP, Orme JF Jr, Weaver LK, Thomas F, et al. Final report computerised protocol controlled clinical trial of new therapy which includes ECCOR for ARDS [abstract]. Am Rev Respir Dis 1992;145:A184.

12 Clemmer C, Morris AH, Suchyta M, Wallace CJ, Orme JF Jr, Menlove R, et al. Extracorporeal support does not improve ARDS survival. Crit Care Med 1992;20:S61.

13 Zapol WM. A Nordic ECMO saga or whither ECMO? Intensive Care Med 1991;17:69-70.

\title{
Lessons from measles vaccination in developing countries
}

\section{Vaccination should be introduced only after rigorous trials with mortality as an end point}

Controlling measles with standard titres of measles vaccine has been limited by the difficulties of reaching and sustaining high enough coverage and the need to delay vaccination until most infants have lost maternal antibody (about 9 months of age in developing countries and 15 months in developed countries). A vaccine that is effective in younger infants is desirable both to protect children before they are exposed to natural measles infection and because attendance at vaccination sessions tends to fall as children get older.

Edmonston-Zagreb vaccine was shown to be immunogenic in high concentration at the ages of 4-6 months in several countries, and in 1989 the World Health Organisation recommended its use in countries where measles before the age of 9 months is a substantial cause of death. ${ }^{1}$ Shortage of high titre vaccines led to delays in the implementation of this recommendation, and it was subsequently rescinded after data from three countries with high background infant mortality (Guinea-Bissau, Senegal, and Haiti) showed increased overall mortality among children who received high titre vaccines at 4-6 months compared with recipients of standard titre vaccines at age 9-10 months. ${ }^{2}$ This unexpected finding had several surprising features. Firstly, the excess mortality did not occur until the second year of life or latera considerable time after vaccination. Secondly, the excess was particularly pronounced in girls. Thirdly, the excess was non-specific, representing the usual range of childhood death in the countries concerned. An independent combined analysis of the findings, commissioned by the WHO, estimated that mortality was significantly increased (averaging $20 \%$ ) and noted that the design of the trials did not allow definitive identification of the concentration or the strain of vaccine as the potential cause of the excess. ${ }^{3}$ If trials had not been carried out with long term mortality as an end point the effect would probably not have been detected as the reporting of vital events is notoriously incomplete in developing countries.

Responses to the findings have been of three kinds. Firstly, the scientific community and funding agencies have rediscovered measles. The National Institutes of Health in the United States issued a call for proposals to investigate the phenomenon. Secondly, new technological approaches are being used to develop measles vaccines that may be effective in the first few months of life. Thirdly, public health authorities, relying on standard titre vaccines in their battle against the measles virus, have adopted new strategies. Some have advocated similar mass campaigns to those that have proved so effective against poliomyelitis in the Americas. Others have proposed schedules of two doses of vaccine with the aim of protecting those who fail to seroconvert after the first dose. ${ }^{4}$ Regimens of two doses, with both given after maternal antibody has waned, have been used in many developed countries for at least a decade, and their apparent safety there is accepted as indicating their safety in the developing world.

In developing countries, however, "early" schedules of two 
doses, with both doses given in the first year of life, have been recommended in populations at risk of morbidity and death from measles before 9 months of age. ${ }^{5}$ The relative efficacy of these strategies in terms of reducing mortality, and their safety, has not been formally tested. The results of the analysis by Aaby et al in this week's journal are reassuring in that mortality unexpectedly falls with standard titre vaccine before 9 months of age (p 1308). ${ }^{6}$ Residual confounding is, however, always a potential problem in observational studies, and, although Aaby et al provide considerable evidence that children differed only by their age at vaccination, there can be no substitute for a randomised trial, particularly when the mechanism of the potential adverse reaction or benefit is not understood.

The finding of excess mortality after high titre vaccines has focused attention on immune function after measles and measles vaccines. The parallels to the delayed excess mortality seen after natural measles raises the suspicion that high titre vaccines, like natural measles, cause long term disruption of immune function, including an imbalance in the type of helper $\mathrm{T}$ cell response. ${ }^{7}$ Aaby et al suggest that standard titre vaccines reduce overall mortality by general immunostimulation. The assays needed to investigate these hypotheses are far from the simple measurement of measles specific IgG, the outcome measure used in over $90 \%$ of the reported trials of measles vaccines in young infants.

The message is clear. Strategies involving vaccination in infants with maternal antibody, or new measles vaccines, must be tested in randomised trials in which the end point is mortality and not a surrogate effect such as measles antibody titre.

A J HALL

Senior lecturer

F T CUTTS

Senior lecturer

Communicable Disease Epidemiology Unit,

Department of Epidemiology and Population Sciences,

London School of Hygiene and Tropical Medicine,

London WC1E 7HT

1 Expanded Programme on Immunisation. Measles immunisation before 9 months of age. Whkly Epidemiol Rec 1990;65:8.

Expanded Programme on Immunisation. Safety of high titre measles vaccines. Wkly Epidemiol Rec 1992;67:357-61.

3 Halsey NA. Increased mortality after high titre measles vaccines: too much of a good thing. Pediatric Infect Dis 9 1993;12:462-5.

4 Tulchinsky TH, Ginsberg GM, Abed Y, Angeles MT, Akukwe C, Bonn J. Measles control in developed and developing countries: the case for a two-dose policy. Bull WHO 1993;71:93-103.

5 Expanded Programme on Immunisation. Global Advisory Group. Measles. Wkly Epidemiol Rec 1993;68:14-5.

6 Aaby P, Andersen M, Sodemann M, Jakobsen M, Gomes J, Fernandes M. Reduced childhood mortality after standard measles vaccination at 4-8 months compared with 9-11 months of age. $B M \mp$ 1993;307:1308-11.

7 Griffen DE, Ward BJ. Differential CD4 T cell activation in measles. $\mathcal{I}$ Infect Dis 1993;168:275-81.

\section{Ethnic composition of NHS boards}

\section{Should reflect that of local communities}

One in 18 of Britain's population are black or from ethnic minorities-defined as people "who may be disadvantaged because of their racial background." But the strategic leaders of its health service are almost all white. ${ }^{2}$ Out of 534 appointed chairpersons of authorities and trusts, only four are from black and ethnic minorities says Equality Across the Board, the report from a joint working party of the National Association of Health Authorities and Trusts (NAHAT) and the King's Fund Centre. ${ }^{3}$ All the chairpersons of the boards of regional health authorities are white.

Only 45 of 1531 (3\%) non-executive board members of regional health authorities, NHS trusts, and special health authorities (data from district health authorities were not available) are from black and ethnic minority communities. Yet these chairpeople and non-executive directors are expected to act as champions of the people and ensure that the NHS meets their needs. All crucial decisions-on closures of hospitals or development of new services - must ultimately be approved by them. But how can they hope to act for all people when they have only limited undertstanding of how a section of them live and think?

That NHS boards do not reflect the racial composition of their local communities is unsurprising, given that people from ethnic minorities are rarely appointed to public positions. The Cabinet Office found that people from ethnic minorities fill only $2 \%(820)$ of about 41000 listed posts on such bodies as the National Curriculum Council and the Wages Council. ${ }^{4}$ Recruitment here, as elsewhere, is likely to follow the well established pattern of recruiting in one's own image, and those responsible for these appointments are usually white. Only six of the 650 members of parliament are from ethnic minorities.

Should the NHS be criticised for not doing better than other employers in the public sector? Equality Across the Board argues that NHS boards need people from ethnic minorities to help them to meet the targets in the Health of the Nation. Ethnic minority communities not only have special problems; they often have worse problems. They find it more difficult than white people to obtain treatment from the NHS either because of working patterns or language problems. The government has made it clear that authorities will be expected to provide the services and health education strategies that are specifically geared to ethnic minority communities and to ensure that these services do not discriminate on racial grounds. In 1991 William Waldegrave, then secretary of state for health, said that one way to ensure that the needs of ethnic minority communities are fully taken into account "is to consider good, suitable candidates from those communities for health authorities' appointments."

Since then the Department of Health has set a goal to increase the proportion of people from ethnic minorities on NHS boards to $4 \%$ by September 1996 . Its new health appointment unit will keep details of the ethnic origin of people appointed to the boards. Its goal is achievable because the responsibility for appointing most of these posts ultimately rests with the secretary of state for health.

Equality Across the Board says that, although there are skilled people from ethnic minorities to fill these posts, current recruitment procedures still exclude them. A survey carried out by Warwick University showed that new board members are often recruited informally, through word of mouth, by chairpeople and chief executives. Usually lacking a network of black acquaintances they are unlikely to recruit a diverse range of new board members.

Even when authorities and trusts consult outside organisations for nominations, people from ethnic minorities can still be excluded. Many authorities consult senior managers in large commercial companies and professional bodies. The labour force survey, however, indicates that people from ethnic minorities are unlikely to be found in management 